\title{
Kati Chu BSS External Genital Organ Delivery Syndrome: Inguinal Pedicle Flap Plasty
}

\author{
Koniba Keita ${ }^{1 *}$, Sidiki Keita ${ }^{2}$, Oulematou Coulibaly ${ }^{3}$, Abdoulaye Diarra1, Fodé Mory Keita1, \\ Boubacar Kone1, Lassina Traoré1, Salia Coulibaly4, Amadou Traoré5, Assitan Kone1, \\ Amadou Kassogué6, Issa Traoré1, Oumou Traoré1, Ismael Konaré1, Daouda Diallo7, \\ Drissa Traoré ${ }^{8}$, Bacary T. Dembélé 5
}

\author{
${ }^{1}$ General Surgery Department, Hospital BSS, Kati, Mali \\ ${ }^{2}$ General Surgery “A” Department, Hospital Point-G, Bamako, Mali \\ ${ }^{3}$ Reference Health Centre of the Commune VI, Bamako, Mali \\ ${ }^{4}$ Medical Imaging Department, Hospital BSS, Kati, Mali \\ ${ }^{5}$ General Surgery Department, Hospital Gabriel Toure, Bamako, Mali \\ ${ }^{6}$ Urology Department, Hospital BSS, Kati, Mali \\ ${ }^{7}$ Anesthesia Resuscitation Department, Hospital BSS, Kati, Mali \\ ${ }^{8}$ General Surgery “B” Department, Hospital Point-G, Bamako, Mali \\ Email: *konibakeita91@gmail.com
}

How to cite this paper: Keita, K., Keita, S. Coulibaly, O., Diarra, A., Keita, F.M., Kone, B., Traoré, L., Coulibaly, S., Traoré, A., Kone, A., Kassogué, A., Traoré, I., Traoré, O., Konaré, I., Diallo, D., Traoré, D. and Dembélé, B.T. (2021) Kati Chu BSS External Genital Organ Delivery Syndrome: Inguinal Pedicle Flap Plasty. Surgical Science, $12,357-364$.

https://doi.org/10.4236/ss.2021.1211037

Received: September 30, 2021

Accepted: November 22, 2021

Published: November 25, 2021

Copyright $\odot 2021$ by author(s) and Scientific Research Publishing Inc. This work is licensed under the Creative Commons Attribution-NonCommercial International License (CC BY-NC 4.0). http://creativecommons.org/licenses/by-nc/4.0/ (c) (i) (5) Open Access

\begin{abstract}
Fournier's syndrome is a poly microbial necrotizing fasciitis, of severe evolution of the perineum and external genitals. Objectives: We report the experience of the service in the management of Fournier gangrene of the external genital organs by inguinal flap pediculated in front of the loss of significant substances of the scrotum. Patients and method: This was a mono-centric retrospective study from January 2008 to August 2021 in the General Surgery Department of the Bocar Sidi Sall University Hospital (CHU BSS) in Kati. It focused on patients treated for Fournier gangrene of external genitals. The variables studied were age, sex, blood count, germs encountered, the antibiogram, duration of evolution, reconstruction of the scrotum by pedicle flap, and morbidity. Results: During the study period we collected 5 cases of Fournier gangrene of external genitals in the service. The average age was 57.6 years and all the patients were male. The average duration of evolution was 5 days for an average age of 57.6 years. All patients were male. Echerichia coli ( E. coli) was the frequently observed germ followed by Enterobacter fécalis (E. fecalis). They were resistant to the usual antibiotics. The germs were $100 \%$ sensitive to imipeneme and nitrofurantoin, $70 \%$ to gentamycin. The wide necrosectomy followed 3 weeks later by the inguinal flap pedicular plasty greatly improved the surgical procedures. Conclusion: Fournier's syndrome is a medical surgical emergency whose prognosis is strongly related to
\end{abstract}


early management.

\section{Keywords}

Fournier's Gangrene, Scrotum, Inguinal Pedicular Flap

\section{Introduction}

Fournier's Gangrene is a necrotizing bacterial dermo-hypodermitis and severe necrotizing fasciitis of perineal regions and genitals. It was first described by Baurienne but it was the French dermatologist Alfred de Fournier who gave his name to the disease in 1883 [1]. It is a rapidly evolving and serious poly microbial infectious process that can be seen at any age. If in the past it was considered idiopathic, nowadays, its etiology is identified in more than three-quarters of patients mainly either a proctological, urological or cutaneous cause [2]. Predisposing factors such as diabetes, alcoholism, HIV infection, extreme ages, poor hygiene have been described [3].

In most of the reported cases, Fournier's gangrene mainly affects male patients of a certain advanced age. Men are ten times more affected than women [4]. This is a rare condition in our daily practice. In Mali, several studies have been reported on this pathology [5] [6] [7], but none have focused on the reconstitution of the scrotum by inguinal flap.

We report the experience of our department in the management of necrotizing bacterial dermo-hypodermitis of external genital organs at the University Hospital Bocar Sidi Sall (CHU BSS) of Kati, while emphasizing the therapeutic aspects.

\section{Patients and Methods}

This was a mono-centric retrospective study from January 2008 to August 2021 in the General Surgery Department of Bocar Sidi Sall University Hospital (CHU BSS) in Kati. It focused on patients treated for Fournier's gangrene of the external genitals. The data were collected from the survey sheets and the operating report register. The variables studied were age, sex, germs encountered, blood count, antibiogram, evolution time, comorbidities, reconstruction of the scrotum by inguinal pedicular flap, and morbidity mortality.

\section{Results}

Five (5) cases of necrotizing bacterial dermo-hypodermitis of the external genital organs (Fournier's gangrene) were collected during the study period in the Kati CHU BSS general surgery unit. The average age was 57.6 years with extremes of 36 to 71 years. The patients were all male and had comorbidities recorded on the table above.

All patients were admitted to the Emergency Department in a Stage $2 \mathrm{WHO}$ 
General Condition Alteration Chart, a fever greater than or equal to $39^{\circ} \mathrm{C}$, pain in the external genitals with smelly odors. The average admission time was 5 days. On clinical examination, we observed a conjunctival pallor, an ulcerothroccus wound taking $2 / 3$ of the base of the bursa often ascending on the base of the penis (Figure 1). The entrance door was anorectal in two patients, urological in the other 3: two cases of benign prostatic hypertrophy $(B P H)$ and one case of urethral narrowing.

The diagnosis was clinical. The bioassay showed anemia at $8 \mathrm{~g} / \mathrm{dl}$ in two patients, and at $9 \mathrm{~g} / \mathrm{dl}$ in the other 3. Neutrophil polynuclear leukocytosis was observed in all five patients. We incidentally diagnosed two comorbidities in a polygamous patient: diabetes mellitus (glucose $2 \mathrm{~g} / \mathrm{dl}$ ) and serology HIV1 and HIV2 positive (human immunodeficiency virus 1 and 2). Cytobacteriological antibiogram examination isolated Escherichia coli, Staphylococcus aureus, Klebsiela pneumoniae, Enterobacter fecalis (see Table 1). The germs were $100 \%$ sensitive to imipeneme and nitrofurantoin, $70 \%$ sensitive to gentamycin.

As soon as the patient was admitted, biological samples (blood and pus) were taken. Broad-spectrum probabilistic antibiotic therapy was immediately introduced with ceftriaxone injectable, gentamycin injectable and metronidazole infusion. Later antibiotic therapy was adapted to antibiogram. We performed a

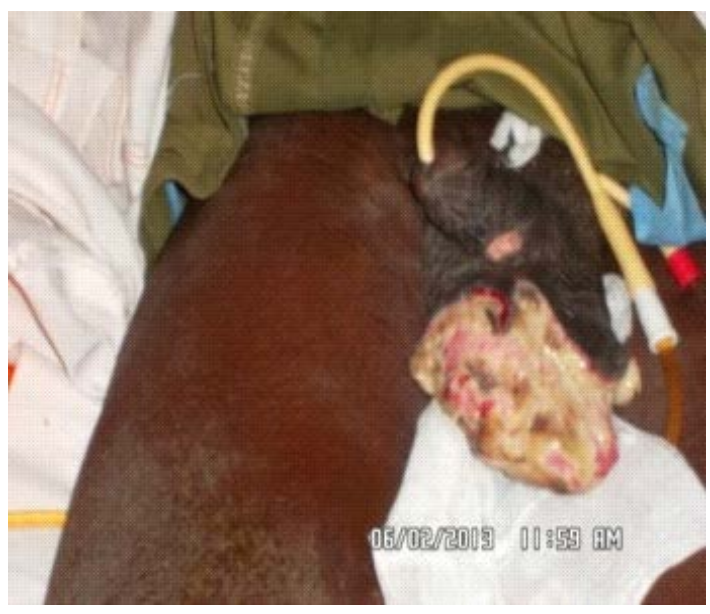

Figure 1. Ulceronecrotic wound testicles.

Table 1. Patient characteristics.

\begin{tabular}{cccccc}
\hline \multirow{2}{*}{ Patients } & \multicolumn{2}{c}{ Demographic characteristics } & \multicolumn{2}{c}{ Culture + antibiogram } \\
\cline { 2 - 6 } & Age & Sex & Comorbidity & Germs & Sensitivity \\
\hline 1 & 60 & male & $H P B$ & E. coli \\
2 & 71 & male & $H P B+$ Diabetes & E. fecalis & Imipenèmes \\
3 & 70 & male & Anal Abcess & S. auréus & Nitrifurantoïnes \\
& & & Narrowing & K. pneumoniae + & Gentamycin \\
4 & 36 & male & uréthral & S. auréus & $70 \%$ \\
5 & 51 & male & Anal Abcess, AIDS, Diabetes & E. coli + E. fecalis \\
\end{tabular}


wide neccrosectomy with washing drainage of the abscesses under general anesthesia during the first forty-eight hours. The dressing was twice daily during the first week of admission. The patient first bathed in a solution of potassium permanganate ( 1 tablet for 5 litres of water) for 15 to 20 minutes and the wound was cleaned clean with hydrogen peroxide. The potassium permanganate solution was renewed with each dressing and the devitalized tissue was gradually excised. Trans-urethral urinary bypass was performed in all patients using the Foley Hinge 12 probe. Tetanus serovaccination has been done in all of our patients. In 5 days the putrid fumes had disappeared as well and the progression of necrosis. In 3 weeks of dressing, the wounds became clean, pink with formation of granulation tissue. The testicles were bare because of the significant loss of skin substance (Figure 2 and Figure 3).

All comorbidities were handled correctly by internist and diabetologist colleagues. $B P H$ cases have been medically treated. After $4-6$ weeks, patients were scheduled for well-healed inguinal pedicular flap repair surgery (Figure 4) (Figure 5). This indication was related to the extent of loss of skin substance.

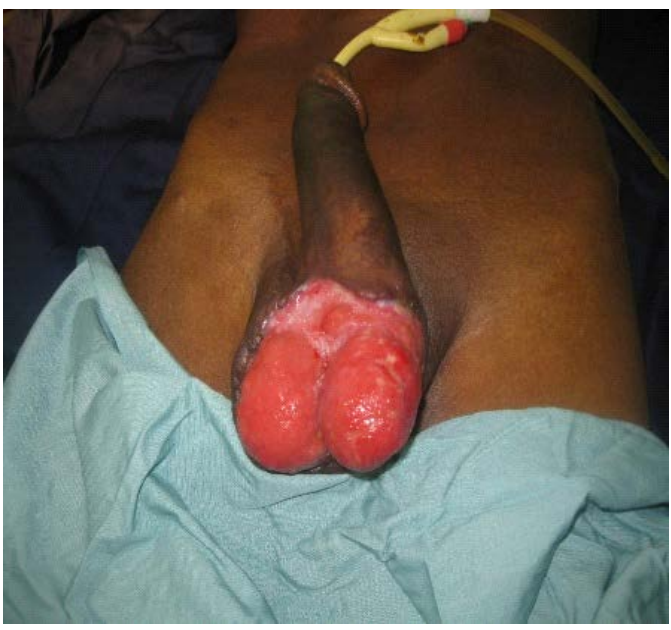

Figure 2. Clean wound.

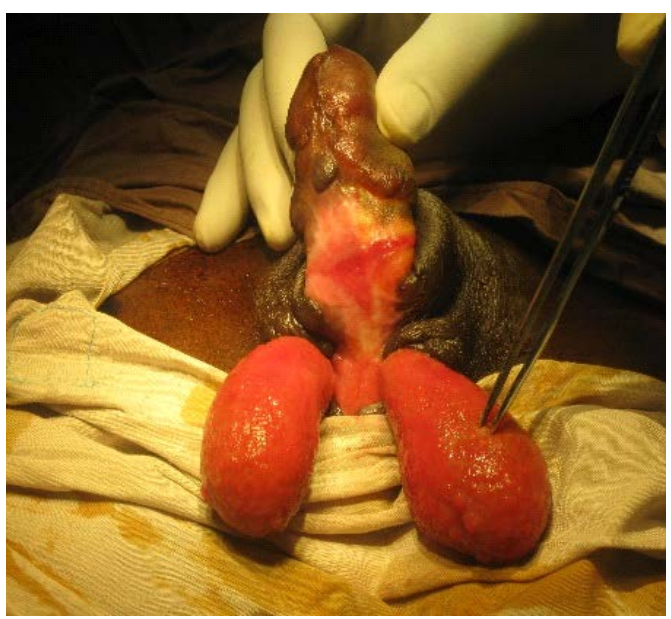

Figure 3. Bare testicles. 


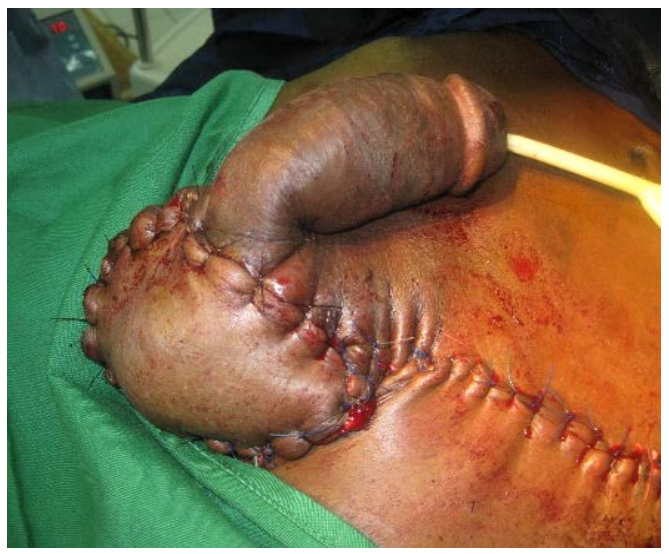

Figure 4. Inguinal flap.

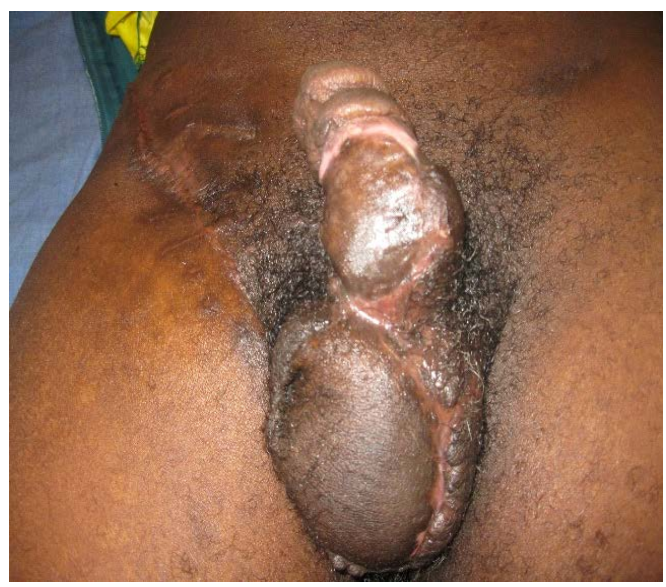

Figure 5. Scarred inguinal flap.

Only a patient has a secondary suture. The HIV-positive (HIV1 and HIV2) diabetes patient developed trans-sphincter anal fistula two months later after discharge. It was resumed where a fistulectomy with slow section of the sphincter on elastic link was performed. The surgical follow-up was satisfactory, average length of stay in hospital was 45 days with zero mortality.

\section{Discussion}

Limitations of the study: The limited number of cases somewhat taints the scientific scope of this study. However, the inguinal flap surgical technique used to cover the testicles would be a first reported in our country. So, we wanted to report our little experience in the surgical management of this disease.

Fournier's gangrene of the external genito-organs is a rare pathology in developed countries [8]. However, it is quite common in Asian and African series [9] [10]. In Mali, authors [6] [7] reported a frequency of 7 to 7.5 cases per year. Male predominance with an average age around 60 is frequently reported in the literature [9] [10]. All of our patients were male, with an average age of 57. Although Fournier's gangrene can be encountered at any age, it is, however, the prerogative of older men whose average age exceeds 50 years. According to Nan 
Zhan [9] the best drainage of secretions in the basin in women is the cause of the rarity of this pathology in them.

Comorbidities are numerous in this pathology and are dominated by diabetes, AIDS, proctological and urological pathologies. According to Geraci G [11] Fournier's gangrene is not an idiopathic pathology, there is always a contributing factor that must be researched and identified. Our data are consistent with that described in the literature [8] [9]. As reported by the authors [10] [12], the diagnosis of Fournier's gangrene is clinical. Before any progressive inflammation or necrosis of the perineoscrotal area and or external genitals in a febrile context, we must think about Fournier's gangrene. We'll always be looking for subcutaneous crackling caused by anaerobic bacteria. This subcutaneous emphysema is a crucial sign in Fournier's gangrene.

Our patients were received in a table of necrosis and fistulization of the bursa or skin of the penis. The diagnosis being obvious we did not make morphological examinations such as ultrasound or computed tomography as in Fernando [8] and Ossama B [10]. These tests are often necessary not only to support the diagnosis but also to delineate the extent of infection by highlighting the presence of gas under the skin. In this study, Escherichia coli was the germ frequently isolated often in association with other bacteria see table. The authors [5] [9] [13] made the same remark in their study. From a therapeutic point of view, the medical component consisted of resuscitation measures, crystalloid infusion and empirical, probabilistic triple antibiotic therapy directed against gram-positive, gram-negative and anaerobic bacteria. The combination of 3rd generation cephalosporin (ceftriaxone) with aminosides (gentamicin) with metronidazole in infusion was the scheme adopted in the service. Jonathan R [14] had observed the same probabilistic therapeutic attitude. This antibiotic therapy was subsequently adjusted based on the results of the antibiogram. The germs identified were all susceptible to imipeneme and $100 \%$ nitrofurantoin. As reported in the Diarra A study [15], the resistance of germs to ordinary antibiotics deserves a deep reflection in order to make behavioural changes in our antibiotic prescriptions. The immediate management of comorbidities (diabetes and AIDS) associated with antibiotic therapy has made it possible to quickly control the infection. While the surgical component of broad antibiotic-covered neccrosectomy is considered the "Gool standard" in the management of necrotizing fasciitis, all of our patients have benefited from it. This therapeutic attitude is consistent with that of literature [10] [11] [14]. In addition, the multiplicity of daily dressings ( 2 to 3 times a day) in our patients as recommended also by Mohamad Moussa [13] allowed a rapid detersion of the wound and control the infection while promoting the formation of granulation tissues. Our patients did not have a protective colostomy because necrosis was only for the bursa. This technique finds its indication in anorectal disorders as reported by Ali E [16]. For testicular skin reconstruction, the inguinal pedicular flap was used in 4 patients. It found its indication in the importance of the skin defect which represented about 80 to 


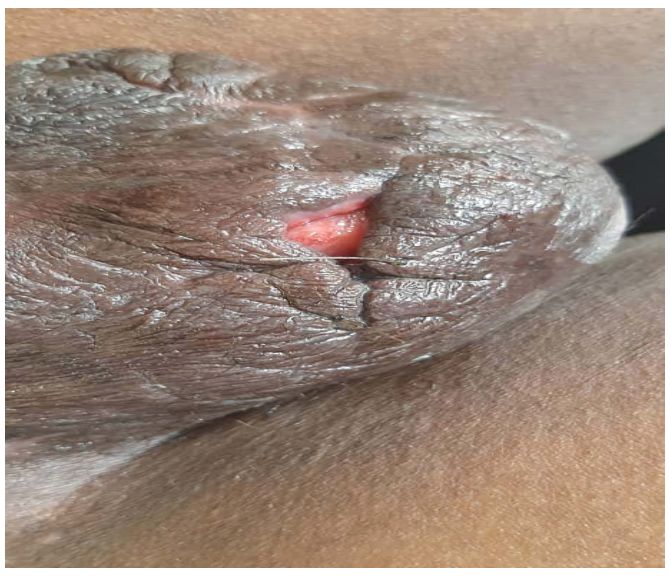

Figure 6. Secondary suture in healing process.

90\% of loss. Cannistra C [17] had adopted the same surgical attitude in his study. He pointed out that this flap is relatively thick, sensitive with modest scar and functional remnants. Only one patient received a secondary suture skin plasty (Figure 6). The procedures were simple, we did not observe any necrosis of the flap.

If the use of hyperbar oxygen or negative pressure wound vacuum (VAC) treatment is adopted in developed countries, we do not have these technologies in our country.

The mortality rate was zero $0 \%$. This could be explained by the absence of septic shock in our patients as in the Sanogo ZZ study [5]. In contrast, the authors [6] [9] [10] reported mortality rates of $8.3 \%, 16.17 \%$ and $18 \%$ respectively. Note that advanced age, the extent of necrosis associated with existing comorbidities (AIDS, diabetes) are factors of poor prognosis.

\section{Conclusion}

Fournier's gangrene of the external genitals is a serious infection whose management requires urgent and vigorous action. Isolated germs were $100 \%$ sensitive to imipeneme and nitrofurantoin. Resistance to ordinary antibiotics is a serious problem. The inguinal pedicular flap is a major indication in cases of loss of extensive substances from the bursa.

\section{Conflicts of Interest}

Authors do not declare any conflict of interest.

\section{References}

[1] Vargas, F. and Boyer, A. (2011) Chapitre 53: Gangrène de Fournier. URGENCES 2011, 601-608. https://sofia.medicalistes.fr/spip/IMG/pdf/Gangrene_de_Fournier.pdf

[2] Fajdic, J., Bukovic, D., Hrgovic, Z., et al. (2007) Management of Fournier's Gangrene-Report of 7 Cases and Review of the Literature. European Journal of Medical Research, 7, 169-172. 
[3] Norton, K.S., Johnson, L.W., Perry, T., et al. (2002) Management of Fournier's Gangrene: An Eleven-Year Retrospective Analysis of Early Recognition, Diagnosis, and Treatment. The American Journal of Surgery, 68, 709-713.

[4] Eke, N. (2000) Fournier's Gangrene: A Review of 1726 Cases. British Journal of Surgery, 87, 717-728. https://doi.org/10.1046/j.1365-2168.2000.01497.x

[5] Sanogo, Z.Z., Ouattara, Z., Yena, S., Doumbia, D., Coulibaly, Y., Tembely, A., Sangaré, D. and Soumaré, S. (2006) Skin Gangrene. Médical, 21, 35-41.

[6] Tchuisi, D. and Riche, C. (2019) Diagnostic and Therapeutic Aspects at the Department of General Surgery and Urology of CHU Gabriel Touré. FMOS Thesis, University of Science Technical and Technologies De Bamako, Bamako.

[7] Kokaïna, S. (2021) External Genital Gangrene: Clinical, Diagnostic, Therapeutic and Evolutionary Aspects at the Urology Department of Chu Gabriel Touré. FMOS Thesis, University of Science Technical and Technologies De Bamako, Bamako.

[8] Fernando, R.A., Andrew, G. and Latha, G. (2021) Fournier's Massive Necrotizing Gangrene. Urology Case Reports, 38, Article ID: 101689.

https://doi.org/10.1016/j.eucr.2021.101689

[9] Zhang, N., Yu, X., Zhang, K. and Liu, T.J. (2020) A Series of Retrospective Cases of Fournier's Gangrene: Necrotizing Fasciitis of the Perineum and Perianal Region. BMC Surgery, 20, Article No. 259. https://doi.org/10.1186/s12893-020-00916-3

[10] Baraket, O., Triki, W., Ayed, K., Hmida, S.B., Lahmidi, M.A., Baccar, A. and Bouchoucha, S. (2018) Therapeutic Factors Affecting Scarring during Perineal Gangrene. The Pan African Medical Journal, 29, Article No. 70.

[11] Geraci, G., Pisello, F., Lupo, F., Cajozzo, M., Sciumè, C. and Modica, G. (2004) Gangrène de Fournier: àpropos d'un cas et revue de la littérature récente. Annali Italiani di Chirurgia, 1, 97-106.

[12] Mallikarjuna, M.N., Vijayakumar, A., Patil, V.S. and Shivswamy, B.S. (2012) Fournier's Gangrene: Current Practices. International Scholarly Research Notices, 2012, Article ID: 942437. https://doi.org/10.5402/2012/942437

[13] Mouhamad, M. and Mouhamed, A.C. (2019) Isolated Gangrene from Fournier's Penis: About a Case and Revered from the Literature. International Journal of Surgery Case Reports, 62, 65-68. https://doi.org/10.1016/j.ijscr.2019.08.012

[14] Rad, J. and Foreman, J. (2021) Fournier Gangrène. StatPearls Publishing. https://www.ncbi.nlm.nih.gov/books/NBK549821/

[15] Diarra, A., Keita, K., Tounkara, I., Traoré, A., Koné, A., Konaté, M., Karembé, B., et al. (2020) Surgical Site Infections at Bocar Sidy Sall University Hospital Center of Kati. Mali Médical, 35, 20-24.

[16] Ali, E., Yasamin, T., Michelle, D., Jodi, G., Naushin, H., Ahmed, A., Aube, E. and Stéphanie, L. (2021) Fournier's Gangrene with Dapaglifozin in a Rural Hospital: A Case Report. BMJ Case Report, 14, e237784. https://doi.org/10.1136/bcr-2020-237784

[17] Cannistra, C., Kirsch-Noir, F., Delmas, V., Marmuse, J.P. and Boccon-Gibod, L. (2003) Reconstruction of the Scrotum after Fournier Gangrene by Inguinal Flap. Progrès en Urologie, 13, 703-706. 